\title{
Aportes a los nuevos estudios literarios sobre el tradicionista
}

\section{(Con motivo de los veinte años del Instituto Ricardo Palma)}

\author{
Manuel Pantigoso Pecero \\ mpantigoso@gmail.com \\ Universidad Ricardo Palma
}

\section{Resumen}

En la introducción aparecen algunas ideas eje surgidas del trabajo hermenéutico del Instituto Ricardo Palma. Se examinan algunos de los principales aportes de Palma a los estudios literarios contemporáneos: el nuevo concepto de la historia; su relación con la ficción poética y el ocultamiento de la propia vida; el espíritu integrador como "verdad de la imaginación"; el impulsor de la crítica literaria; su condición de precursor del Modernismo; su afinidad con Garcilaso en el descubrimiento del Perú.

Palabras clave: Ficción, precursor, identidad, integración.

\section{Abstract}

In the introduction appears some axis ideas emerged from the hermeneutic work of the Ricardo Palma Institute. Some of the main contributions of Palma to the contemporary literary studies are examined: the new concept of history; his relation with poetic fiction and the concealment of the own life; the conciliatory spirit as "truth of the imagination"; the impeller of the literary criticism; his condition as forefather of Modernism; his affinity with Garcilaso in the discovery of Peru.

Keywords: Fiction, forefather, identity, integration. 


\section{Manuel Pantigoso Pecero}

Poeta, crítico literario y de arte, dramaturgo y maestro universitario, promotor cultural y periodista. Doctor en Literatura y Filología y Doctor en Educación. Profesor Emérito de la Unmsm. Director de la Oficina Central de Extensión Cultural y Proyección Social de la U.R.P. Presidente del Instituto Ricardo Palma. 


\section{Introducción}

El Instituto que lleva el nombre egregio de Ricardo Palma inició en 1997 su tarea de recoger y analizar la creación histórico-literaria a la que el ilustre escritor prodigara su esfuerzo y energía durante toda su existencia. Estamos, pues, cumpliendo dos décadas de intenso trabajo y elocuentes resultados.

En el primer número de la revista Aula Palma -que registró trece discursos de incorporación (1998-1999) - se decía que el Instituto, creado por iniciativa del Rector Iván Rodríguez Chávez, está dedicado "a la investigación humanística y dentro de ella al nuevo examen de la obra magna del tradicionista”. Así lo hemos venido haciendo cada año a través, sobre todo, de los encuentros anuales denominados "Re-Visión de las Tradiciones" en donde, con renovadas lecturas de la obra general de Palma, participan los Miembros de Número del Instituto, los Miembros Correspondientes a nivel nacional y del extranjero, los estudiosos que vienen de distintas universidades del país y, también, los invitados especiales.

Nuestra Corporación cumple, así, una labor orientadora, de nuevos exámenes, de leer con atención a la luz de una visión crítica permanente. Ella se constituye, por eso, en el mayor referente en

l Estuardo Núñez, Ricardo Palma en el tiempo y en el espacio; Wilfredo Kapsoli Escudero, Biografía del libro El Demonio de los Andes de Ricardo Palma; Iván Rodríguez Chávez, La crítica literaria en La Bohemia de Palma; Dora Bazán de Devoto, Ricardo Palma, pionero de los estudios terminológicos; Manuel Pantigoso Pecero, El sentido del pasado y la actualidad de la lengua en las Tradiciones de Palma; Roberto Reyes Tarazona, La Lima de Ricardo Palma; Pedro Díaz Ortiz, Las Tradiciones como género literario; Marco Martos, Anales de la Inquisición de Lima, Ricardo Palma, la vela verde y el sambenito; Carlos Eduardo Zavaleta, Naturaleza y estructura de la Tradición de Palma; Oswaldo Holguín Callo, Ricardo Palma, el Ecuador y los ecuatorianos; Manuel Velázquez Rojas, El humorismo en las Tradiciones de Ricardo Palma; Ricardo González Vigil, Ricardo Palma entre el cuento y la novela; José Antonio Bravo, Por una aproximación a la multiplicidad de niveles de lectura en las Tradiciones Peruanas de don Ricardo Palma. 
el Perú y en el extranjero de los estudios dedicados al patriarca de nuestras letras. Contamos con la honrosa participación de escritores especialistas de América, Europa y Asia. ${ }^{2}$

La reflexión y el análisis de la obra palmista ha dado como resultado la publicación de cerca de trescientos ensayos producto de los encuentros anuales de octubre referidos a la trayectoria periodística, literaria, poética, política, histórica, social, editorial, crítica, etc., de Palma, con todo lo cual se tiene una mejor visión de su aporte a la literatura y a la identidad cultural del país.

Esta re-visión anual tiene su fundamento en el hecho de que los aportes existentes, sin duda valiosos, de Porras, Mariátegui, Haya de la Torre, Vargas Llosa, Cornejo, Oviedo, etc., se han venido repitiendo hasta el cansancio cometiéndose en el camino excesos, deformaciones y estancamientos que no toman en cuenta el hecho de que el tiempo y el espacio narrativo para un clásico como Palma no permite que se le endilgue a su obra ese motete de "arcadia colonial" sustentada, primero, por Manuel González Prada, y luego por Sebastián Salazar Bondy en Lima la horrible, que conspirara contra esa actualidad permanente que rodea a las Tradiciones. Ahora, gracias a los nuevos aportes de los investigadores del Instituto, es posible percibir cómo ha ido cambiando la percepción sobre una obra que, además, no comprende solo las Tradiciones, ubicada en la línea que continúa las crónicas de Indias, sino mucho más: poesía, crónica, crítica literaria, ensayo, periodismo, etc. Veamos algunos aportes significativos en el campo de lo literario.

2 Lamentablemente, el ilustre representante del África doctor Kouakou Koffi, el único que tuvimos, falleció poco después de volver a su país luego de participar en el evento del 2010. 


\section{El concepto moderno de la historia y de lo real maravilloso en la obra de Palma}

Actualmente el concepto mismo de historia ha variado. Obras como las del Inca Garcilaso de la Vega o de Guaman Poma de Ayala no son tomadas al pie de la letra sino por lo que subyace en su esencia literaria, es decir, por lo que revela esa ficción literaria. Ocurre algo similar con Palma cuyos trabajos califican hoy día dentro del género de la "ficción histórica", con lo cual se corrige la postura inflexible de González Prada. Si bien los textos del tradicionista son episodios sazonados por el ingenio individual, él repasa fuentes bibliográficas para luego ambientarlas en un momento dado, respetando hasta donde es posible situaciones y locaciones a las que ellas se refieren ${ }^{3}$. En esa ambientación está el costumbrismo de Palma, a flor de labio, con la chispa y el deleite de narrar aunque se trate de hechos, personajes y lugares casi perdidos en la lejanía del tiempo. El escritor se acerca a la sintaxis actual cuidando que el léxico aunque los hechos pertenezcan a los siglos XVI o XVII, o más adelante- tenga el nivel de la lengua propia de las crónicas del momento en que se escriben.

La fuente abierta e inagotable de la Conquista y del Virreinato fue para Palma documental valioso que tendría, a su vez, decisiva influencia en muchos narradores peruanos que empezaron a producir textos de temática histórica a partir de la década de los ochenta del siglo $\mathrm{XX}^{4}$. Entre ellos debemos destacar a José

3 Los trabajos del doctor Lorenzo Huertas Vallejos, Miembro del Instituto, sobre las injurias del tiempo demuestran que los registros históricos de Palma son fidedignos y, por eso, verificables.

4 Esta tendencia se verifica en autores como Guillermo Thorndike, en particular su tetralogía sobre la guerra con Chile (1977-1979) y su monumental biografía novelada de Miguel Grau (2006); también Los papeles de Damasco (2006), de Jorge Salazar. Una obra singular es el texto de Fernando de Trazegnies que une el ensayo jurídico (de Filosofía del Derecho) con la investigación histórica y la composición de una novela histórica: En el país de las colinas de arena (2 vols., 
Antonio Bravo quien en Barrio de Broncas (1972) incorpora el universo popular urbano junto con las, por entonces novedosas técnicas narrativas; y al lado de ellas la creación de un lenguaje que retrata los giros y modos de los habitantes de la urbe limeña de los años cincuenta y sesenta. En esta obra el lector se deleita con el estilo empleado y con la filiación palmista que Bravo no rechaza sino, al contrario, se enorgullece de ella. La novela alcanza niveles históricos en varios capítulos y secuencias y tiene "toques" de lo real maravilloso. No se descarta que estos escapes imaginarios de José Antonio Bravo provengan, también, entre otros vínculos, de las lecciones recibidas de la misma narración palmista en donde ya estaría gestándose esa corriente literaria que tendría en García Márquez a un genial representante.

\section{El estilo y la relación directa con la ficción como "verdad de la imaginación"}

En las Tradiciones de Palma es posible verificar la existencia de otra realidad permanente: la de la obra literaria. Ella se encuentra en el ámbito de la ficción, la única capaz de construir la utopía, de darle forma al deseo de traer hacia nosotros lo lejano o lo imposible. Recordemos, de paso, que el sentido tradicional de la palabra "utopía" significó para los humanistas la imaginaria construcción de un mundo perfecto como respuesta crítica a una existencia defectuosa. En la narrativa de Palma, en cambio,

1994). De otro lado, Miguel Gutiérrez ensaya el relato histórico en la Violencia del tiempo y en su ensayo-novela Poderes secretos. Fernando Iwasaki ha reconstruido con visión fresca la etapa virreinal en Inquisiciones peruanas y Neguijón; por su lado Cromwell Jara ha escrito sobre las peripecias de la población afroperuana, en Babá Osaím, cimarrón, ora por la santa muerta (1990); y Luis Nieto Degregori y Enrique Rosas Paravicino han revivido el pasado cuzqueño. También Luis Enrique Tord ha plasmado libros de relatos que indagan sobre el imaginario mítico y simbólico de nuestro mestizaje: Oro de Pachacamac (1985), Espejo de constelaciones (1991) y Fuego secreto (2006). Sin duda, la obra de José Antonio Bravo tiene una impronta palmista más que evidente. 
utopía es lo que luego se llamaría "visión lúcida" o forma de la "imaginación crítica", porque en ella habita de múltiples maneras -a veces muy veladas por la ironía, el humor y el ingenio- el inconformismo y la exigencia capaces de impulsar una realidad más auténtica y duradera.

De manera esclarecida Raúl Porras Barrenechea diría sobre esa fusión lúcida, plena de imaginación que no desecha la crítica: "Palma no concibe la historia sin un algo de poesía y de ficción. Incapaz de ceñirse a un texto frío él adereza la historia, la anima y la retoca, y cuando el manuscrito tiene claros (...) él lo llena con las telarañas de su ingenio" (Porras Barrenechea, 2008: 95). Aquí está también presente ese espíritu integrador, poliédrico y verosímil, que es característica esencial de la modernidad narrativa: los hechos imaginados en la ficción de la fantasía corresponden a la "verdad de la imaginación".

\section{La ficción poética como ocultamiento de la propia vida dentro de la narración}

"y para enmascarar mi pobre espíritu recurro de la broma al antifaz..."

(“Cháchara" 1875)

Tanto la vida como la obra de Palma se estrechan en una tríade indesligable, de verdad-mentira-verdad, como expresión y como impronta estilística. Varios pasajes de su misma existencia parecen extraídos de la propia ficción como cuando señaló que se había desempeñado como Cónsul en Belem do Pará, en Brasil: lo que sí sucedió es que siguiendo la ruta de entonces fue primero a Europa. Según el estudioso Oswaldo Holguín Callo, miembro de nuestro Instituto, Palma arribó a ese gran país pero nunca asumió esa función porque otras razones políticas no se lo permitieron (Holguín, 200 1: 41). En la otra orilla estaría el historiador Raúl 
Porras Barrenechea quien -sin mayores pruebas- sostiene lo contrario.

Otro tema materia de controversia fue su paso por el colegio San Carlos. Jorge Guillermo Leguía negaba esta filiación:

He investigado en los libros del Convictorio y no he descubierto ni su matrícula ni sus calificaciones, ni huella alguna de su paso por los claustros de la calle del Noviciado. Yo tengo la certidumbre de que el gran escritor, entonces en potencia, no pisó las aulas de Herrera. (Guillermo, 1934: 13)

En cambio Oswaldo Holguín señala que la presencia de Palma en el colegio Carolino está suficientemente probada.

Respecto a su origen racial, Palma no hizo referencia específica a sus raíces mulatas. Simplemente las ocultó o las guareció, por causa de los prejuicios, dentro de una niebla propia más bien del difuso espejo de la poesía. Inclusive la palabra "pardo", con la cual se le describía físicamente en su partida de bautismo, fue entendida como su apellido materno. En realidad su madre se apellidaba Soriano.

Agreguemos también esa disposición de Palma por recrear -con otros datos y con su estilo- las narraciones que le enviaban sus "informantes", como Clorinda Matto de Turner, desde el Cuzco; Celso V. Torres, desde Caraz; Mariano Ambrosio Cateriano, desde Arequipa; Marco A. De la Fuente, desde Lambayeque; y otros de Puno, Ica y Tacna. Alguno de sus detractores criticaron esta postura, pero Palma no les dio importancia por ese típico enrarecimiento de la realidad con el que selló su estilo.

Respecto a la duda sobre el episodio de la novela Los Marañones esta aparece, entre otros, en lo escrito por Estuardo Núñez. Queremos transcribir el párrafo respectivo que, en sí mismo, 
es elocuente para resaltar ese estilo de Palma impulsado por la imaginación:

Palma informó textualmente que habría empezado y concluido de escribir una novela histórica de "Los Marañones" concebida, según pensamos, siguiendo el modelo vigente en Europa. Pero la novela no llegó a publicarse y pasados quince, años en 1881, los originales por propia declaración del autor desaparecieron quemados en el incendio de su casa de verano, durante la batalla de Miraflores. Nos queda la duda de la real existencia de esos originales que su autor nunca se esforzó en reconstruir; ¿o sería un proyecto fallido de una novela que nunca escribió? (Núñez, 1999: 17)

En algunas tradiciones nuestro escritor se refiere a pasajes de su vida que parecieran, también, ser ficticios o producto de sus invenciones. Así, en la tradición "Una visita al Mariscal Santa Cruz" le recuerda al Presidente de la Confederación Peruano-Boliviana una osadía de la niñez que casi le desbarata sus planes de destierro:

Era en enero de 1839, y se vivía en Lima entre agitaciones y zozobras. Una noche, poco después de las siete, se oyó en la tranquila calle del Rastro de San Francisco, donde habitaba mi familia, galopar de caballos; corrí al balcón, y en la penumbra de la calle, pobrísimamente alumbrada, alcancé a ver un grupo de tres o cuatro jinetes; ocurrióseme que llevaban arreos militares, y, sobre excitada mi imaginación por los relatos que oía continuamente de mi padre, partidario decidido de la Confederación, grité: "iViva Santa Cruz!".

Creí que la cabalgata se había detenido un punto; pero pronto se perdió en las tinieblas. Por averiguaciones 
posteriores he llegado a pensar que no me equivoqué al lanzar mi exclamación.

-Realmente era yo -exclamó don Andrés, que me había escuchado con gran atención- (Palma, 1951: 354).

El talento de Palma se adelantó -como verdadero fundador, o iniciador, de la narrativa peruana y como precursor del "ensayo novelado" (José Antonio Bravo) -a un aspecto contemporáneo de la novela: hacer verosímil o dejar en la sugerencia y en la duda lo narrado. Por esto -más que por haber escrito también poesía-, el escritor peruano dejó en sus propias Tradiciones su verdadera impronta poética.

\section{Uno de los primeros exponentes de la crítica contemporánea}

Es importante tener una visión de conjunto de la obra de Palma para reconocer el hecho de que él fue uno de los primeros en abrir la senda de los estudios críticos en el Perú. Como editor -y también como prologuista- se preocupó en estudiar y comentar las obras publicadas ${ }^{5}$. Un buen ejemplo de penetración crítica es su libro Flor de Amancaes y Diente del Parnaso, aquí Palma, al estudiar y elogiar la producción popular de Caviedes, percibe el reverso de esa poesía almibarada y barroca de los escritores de las veladas dirigidas por el virrey Marqués de Castell-dos-Rius, y muestra la madurez necesaria como para empezar a juzgar una obra literaria. Fue el primero en estudiar en forma panorámica la literatura de la Colonia; y también la de Segura o la de Clorinda

5 La crítica se explaya a sus anchas, también, en las obras prologadas por Palma, entre ellas podemos citar Teatro de Manuel A. Segura (1858); Lira Americana (1865), colección de poesías de los mejores poetas del Perú, Chile y Bolivia; Santa Rosa de Lima (1867), poema histórico de don Luis Antonio de Oviedo y Herrera; Perú, Tradiciones Cuzqueñas (1884); Artículos, Poesías y Comedias de Manuel Ascencio Segura (1885). 
Matto de Turner. Más allá del enjuiciamiento positivo o negativo que hace de los escritores de la Colonia, lo cierto es que con ello demuestra el versado conocimiento de esta literatura.

Esta vena crítica se ha de apreciar con amplitud en Recuerdos de España (1898), que es una semblanza de la época y de sus escritores notables. Pero antes, en su importante La Bohemia de mi tiempo (1886), Palma explica e interpreta el sentido histórico de su generación y remata con un ensayo lúcido que recoge hechos, causas y efectos. Cierne, así, con mayor agudeza y profundidad su instrumento crítico. En un fragmento de este libro destaca con precisión los gustos literarios de sus amigos:

Nosotros, los de la nueva generación, arrastrados por lo novedoso del libérrimo romanticismo, en boga a la sazón, desdeñábamos todo lo que a clasicismo tiránico apestara, y nos dábamos un hartazgo de Hugo y Byron, Espronceda, García Tassara y Enrique Gil. -Márquez se sabía de coro a Lamartine; Corpancho no equivocaba la letra de Zorrilla; para Adolfo García, más allá de Arolas no había poeta; Llona se entusiasmaba con Leopardi; Fernández, hasta en sueños, recitaba las doloras de Campoamor; y así cada cual tenía su vate predilecto entre la pléyade revolucionaria del mundo viejo. De mí recuerdo que hablarme del Macías de Larra o de las Capilladas de Fray Gerundio, era darme por la vena del gusto. (Palma, 1897: 5)

\section{Precursor del Modernismo en tanto cosmopolitismo e innovación}

Dentro de los nuevos estudios que abordan los inicios del Modernismo es crucial la presencia de Palma a partir de la visita que Rubén Darío le hiciera en la Biblioteca Nacional, en 1888. Los aportes actuales demuestran que para modernizar la poesía 
hispanoamericana el autor de Azul se apoyó en lo realizado por el tradicionista, sobre todo en esa necesidad de crear una identidad propia. En el caso de Darío es claro que su escritura estará proyectada hacia el cosmopolitismo y la modernidad. Al respecto, podemos citar los trabajos de Kimberly Louie: Darío Palma y los orígenes del Modernismo latinoamericano y de Juan E. de Castro: Rubén Darío Visits Ricardo Palma: Tradition, Cosmopolitanism, and the Development of an Independent Latin American Literature. Kimberly Louie señala:

A pesar de que Palma escribe justamente sobre las tradiciones peruanas, ello no quiere decir que su escritura se ubique siempre en lo tradicional. Es precisamente lo opuesto, a saber, que el autor peruano satiriza las tradiciones peruanas por medio de la reinterpretación y extensión de la cultura colonial y legado literario. Darío, como extensión de las nuevas perspectivas creadas por Palma, extiende la escritura a la Modernidad en que surge el cosmopolitismo y la innovación. (Loui, 2009: pag. 4)

Por su parte, Juan E. de Castro refiriéndose al tradicionista y a su postura frente a lo moderno expresa lo siguiente: "Es precisamente por el advenimiento de la modernidad por lo que Palma ve la necesidad de crear una identidad nacional propia"6.

Es decir $-\mathrm{y}$ esto es fundamental-, los primeros pasos de Palma son los que permiten a Darío alcanzar esa visión suya sobre una nueva escritura.

6 Ob. cit. 


\section{El espíritu integrador como estilo de Palma}

La proyección de lo histórico y de la ficción literaria así como la función de la imaginación y del ocultamiento, propios de la Tradición, no fueron los únicos rasgos de ese estilo integrador con el cual el gran escritor se identificó ${ }^{7}$. Esta impronta estará también en su copiosa y diversa obra que permite repensar al país como un poliedro capaz de hacer brillar todos los períodos históricos, desde la época incaica. Esta línea propia de un espíritu polifacético se demuestra mediante los diversos ensayos publicados en cualquiera de los números de "Aula Palma”, vocero del Instituto Ricardo Palma, en donde aparecen peruanismos, música y danza, religión, Lima, administración pública, cultura andina, enfermedades, cataclismos, etc. Y al lado de ellos, el sentido social y comunicativo, la política, la historia, la oralidad, la inquisición, el periodismo, la presencia de las provincias, etc.

Esta visión totalizadora de la obra de Palma a la luz de las nuevas lecturas confirma, en un caso, lo estudiado en su momento; en otros rectifica los errores cometidos, descubre otros rasgos de lo encubierto o velado, y amplía el enfoque siempre abierto, creativo. La actual y acuciosa penetración en sus textos tiene que ver con la utilización de nuevas técnicas y metodologías dentro del aparato crítico. Aquí se dan la mano la razón y la sensibilidad, antenas capaces de penetrar en un clásico que, por serlo, se renueva siempre con el paso del tiempo. Sus obras siguen siendo populares años después de su publicación porque los temas allí presentes se revitalizan constantemente: ellos contienen algún tipo de recurso generalizador y universal que permite no solo volver a leerlos sino también ser "reescritos" por otros autores,

7 Palma fue reconocido como un hombre integrado e integrador, especialmente después de la Guerra del Pacífico cuando la unión y la reconstrucción de la Patria así lo exigían. 
peruanos y americanos, que siguen el modelo del maestro.

Todo esto aflora hoy gracias a esa lucidez estilística, integradora, que está en la escritura palmista. Ella le otorga más elementos de juicio a los palmistas del Instituto provenientes de diferentes especialidades. Ellos han incorporado, igualmente, esa impronta multidisciplinaria.

\section{Palma como Garcilaso descubren al Perú}

Igual que los Comentarios Reales, de Garcilaso, las Tradiciones Peruanas son fragmentos de una sola historia: la del espíritu peruano y su trascendencia vital en trance de horadar la realidad para lograr en el descenso hacia lo íntimo- el descubrimiento del propio ser del Perú. Crítico del país fragmentado que le tocó vivir, Palma, con sus Tradiciones, fue uno de los primeros en intentar construir una identidad nacional atemporal. Él, se ha dicho bien, inventó al Perú. Él puso luz sobre sus distintos rincones.

Por su lado, Garcilaso, con sus Comentarios Reales, sentó las bases de la síntesis cultural del destino del país al extender ese hilo conductor de su memoria cuya esencia es lo ético religioso: justicia social y unidad política del incario, por un lado, y síntesis cultural presidida por el evangelio de la conquista, por el otro; mediante este hilo conductor fue posible seguir la fundación del Perú, su conflicto íntimo -nada sereno o apacible-, la descripción de la cordillera, la memoria de la conquista, la nostalgia y el afecto por lo perdido, el tormento por la guerra civil entre los peruanos, las dudas y angustias frente a la conjunción de lo andino y lo español.

En la relación de estos dos grandes escritores es posible verificar que las Tradiciones de Palma tienen el sello de un espíritu que por ser clásico siempre ha de requerir de estudios 
en donde predominen la serenidad, la hondura interpretativa, la interdisciplinaridad. Él efectivamente inventó al Perú y le dio carácter y personalidad. Él puso como base la sensibilidad popular, creadora, retozante, al lado de un humanismo ético y estético que sigue recorriendo la historia patria como una continuidad esencial en el tiempo.

\section{Bibliografía}

Flores Quelopana, G. (2008). Visión del Perú del Inca Garcilaso. Lima: Editorial Iipcial.

Holguín Callo, O. (2001). Páginas sobre Ricardo Palma (vida y obra). Lima: Universidad Ricardo Palma.

Leguía Guillermo, J. (1934). D. Ricardo Palma. Lima: Compañía de Impresiones y Publicidad.

Leguía, J. G. (1934). D. Ricardo Palma. Lima:Louie, K. (2009). Darío, Palma y los orígenes del Modernismo Latinoamericano. Recuperado de:http://magazinemodernista.com/2009/04/12/dario-palma-y-los-origenesdel-modernismo-latinoamericano/.

Núñez E. (1999). Ricardo Palma en el tiempo y en el espacio. Aula Palma. Discurso de Incorporación. Aula Palma. Lima: Universidad Ricardo Palma.

Palma R. (1897). Recuerdos de España : notas de viaje, esbozos, neologismos y americanismos. [S.I.] [s.n.] Buenos Aires Imp. Litogr. y Encuadernación de J. Peuser.

Palma, R. (1899). Recuerdos de España: precedidos de La bohemia de mi tiempo. Lima: Imprenta La Industria. 
Palma, R. (1951). Tradiciones Peruanas, Tomo V y VI. Lima: Editorial Cultura Antártica S.A.

Porras Barrenechea, R. (2008). Palma, la Tradición y el tiempo, Jesús Cabel (comp). Lima: Universidad Ricardo Palma.

Recibido: 30 de septiembre 2016 Aprobado: 25 de octubre 2016 